\title{
Radiographic study of Böhler and Gissane angles in the Brazilian population
}

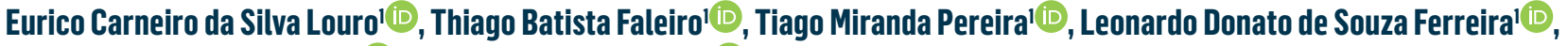 \\ Roberto Guimarães Rezende' $\left(\mathbb{D}\right.$, Tomás Amorim Andrade ${ }^{(\mathbb{D})}$ \\ 1. Hospital Santo Antônio, Obras Sociais Irmã Dulce, Salvador, BA, Brazil.
}

\begin{abstract}
Objective: Determine Böhler and Gissane angles in the Brazilian population and compare them with the data available in the literature. Methods: A total of 800 weightbearing lateral radiographs of the calcaneus were evaluated in adult patients of both sexes. The angles were measured using the digital Picture Archiving and Communication System.

Results: The sample consisted of 800 patients; 554 (69.2\%) were women and 246 (30.8\%), men. In the sample evaluated, the Gissane angle is $110.6 \pm 11.9$, while the Böhler angle is $32.6 \pm 6.1$. No differences were observed in the angles in terms of the comparison between sex and age.

Conclusion: In the Brazilian population, the Gissane angle is $110.6 \pm 11.9$, while the Böhler angle is $32.6 \pm 6.1$. There is no statistically significant difference in the comparison between sex and age.

Level of Evidence IV; Therapeutic Study; Case Series.

Keywords: Calcaneus; Radiography; Population characteristics.
\end{abstract}

\section{Introduction}

The calcaneus is the most frequent tarsal bone to be fractured. The most common trauma mechanism is fall from height, which occurs frequently during professional activity and affects young men ${ }^{(1)}$. About $70 \%$ of these fractures are intra-articular, representing greater difficulty in treatment and a worse prognosis for patients ${ }^{(2)}$.

The Böhler angle was described by Dr. Lorenz Bohler (18851973) in $1931^{(3)}$ and is defined by a line drawn between the highest region of the anterior process and the highest part of the posterior articular surface, and a second line between the same point on the posterior articular surface and the highest point of the calcaneal tuberosity (Figure 1). The literature reports a wide normal range for $A B$, from 20 to 40 degrees $^{(4,5)}$.
The Gissane angle was described in 1947 by Dr. William Gissane $(1898-1981)^{(6)}$. It is defined by two lines, the first of which extends from the lowest point of the posterior facet to the highest point, and a second from the lowest point of the posterior facet to the highest point of the anterior surface (Figure 2). Different normal ranges, such as $96^{\circ}-152^{\circ}, 100^{\circ}-130^{\circ}$, $120^{\circ}-145^{\circ}$, and $95^{\circ}-105^{\circ}$ are reported in different studies ${ }^{(7)}$.

The Böhler and Gissane angles are used to assess calcaneal fractures in the preoperative period to evaluate joint impairment, and in the postoperative period to evaluate reduction quality ${ }^{(8)}$

The aim of this work is to determine the Böhler and Gissane angles in the Brazilian population and to compare them with the data available in the literature.
Study performed at the Hospital Santo Antonio, Obras Sociais Irma Dulce, Salvador, BA, Brazil.

Correspondence: Eurico Carneiro da Silca Louro. 1058 Prefeito Carlos Cruz Av., Franciscanos, Juazeiro do Norte, CE, Brazil, Zip Code: 63050-030. E-mail: euricocsl@gmail.com. Conflicts of interest: none. Source of funding: none. Date received: January 16, 2020. Date accepted: March 19, 2020. Online: April 30, 2020
How to cite this article: Louro ECS, Faleiro TB, Pereira TM, Ferreira LDS, Rezende RG, Andrade TA. Radiographic study of Böhler and Gissane angles in the Brazilian population. J Foot Ankle. 2020;14(1):57-61. 


\section{Methods}

This study was approved by the Institutional Review Board and registered on the Plataforma Brazil database under CAAE (Ethics Evaluation Submission Certificate) number: 79836417.5.0000.0047.

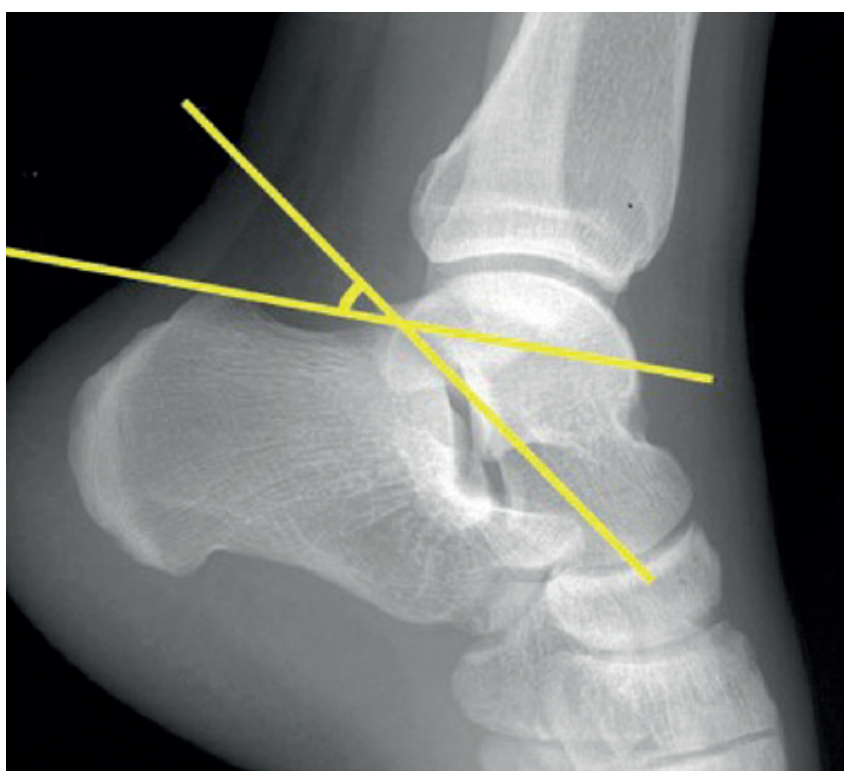

Figure 1. Böhler Angle.

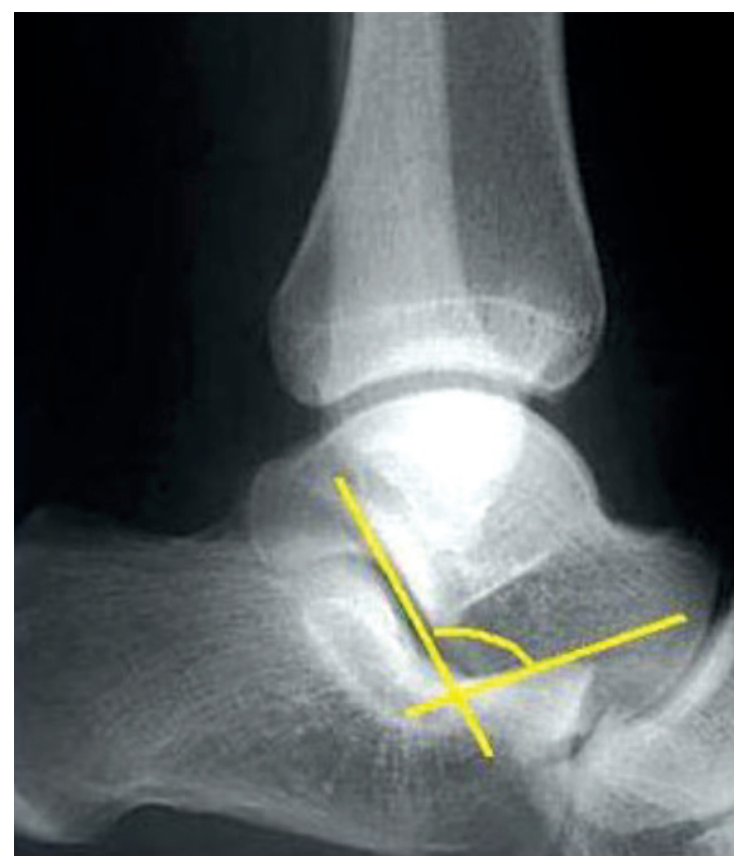

Figure 2. Gissane Angle.
A prospective study was carried out between June 2017 and June 2019 in which 800 weightbearing lateral radiographs of the calcaneus were evaluated in adult patients of both sexes. Convenience sampling was performed by recruiting patients treated at the Foot and Ankle Medical and Surgical outpatient clinic during the study period. Patients with a history of hindfoot (calcaneal or talar) and ankle fracture or radiological signs of subtalar osteoarthritis, characterized by joint space narrowing, osteophyte formation reaction or subchondral sclerosis, were excluded. A total of 86 patients were excluded, 27 due to a history of fracture and 59 because they showed signs of osteoarthritis on the radiographs. Angles were measured using the digital Picture Archiving and Communication System.

For statistical analysis, a definition of normality was made through graphical analysis and the Shapiro-Wilk test. For descriptive analysis, quantitative variables with normal distribution were represented by their mean and standard deviation. Intergroup comparisons were performed using Student's t-test and ANOVA.

Categorical variables were represented through frequencies and percentages. The $\mathrm{Chi}^{2}$ test was applied to perform an intergroup comparison.

Box plots were drawn up comparing the genders of the subjects and the Böhler and Gissane variables.

\section{Results}

Table 1 shows that among the 800 patients, 554 (69.2\%) were women and 246 (30.8\%) men. The mean age of the patients was $50.2 \pm 16$.0. Among the age groups, Table 1 shows the predominance of elderly patients. In the sample evaluated, the Gissane angle is $110.6 \pm 11.9$, while the Böhler angle is $32.6 \pm 6.1$.

Table 1. Sample Characterization

\begin{tabular}{lc}
\hline & Total $(\mathbf{n}=\mathbf{8 0 0})$ \\
\hline Age & $50.2 \pm 16.0$ \\
Gissane & $110.6 \pm 11.9$ \\
Böhler & $32.6 \pm 6.1$ \\
Sex & \\
Female & $554(69.2)$ \\
Male & $246(30.8)$ \\
Age Groups & \\
$18-20$ & $26(3.2)$ \\
$21-30$ & $74(9.2)$ \\
$31-60$ & $126(15.8)$ \\
$41-50$ & $160(20.0)$ \\
$51-60$ & $199(24.9)$ \\
$61-92$ & $215(26.9)$ \\
\hline
\end{tabular}


Table 2 shows that the age among women was $51.6 \pm 15.3$, while the group of men assessed is younger (46.9 \pm 17.0 ), with a statistically significant difference having been observed. On the other hand, there was no statistically significant difference in the value of the Böhler (Figure 3 ) or Gissane (Figure 4) angles between males and females.

When the different age groups were compared, no statistically significant difference was observed for the Böhler and Gissane angles (Table 3).

Studies carried out in different parts of the world have evaluated the Böhler angle of their populations, while others have evaluated both Böhler and Gissane angles. The results presented in Table 4 show that there is no statistically significant

Table 2. Comparison between genders

\begin{tabular}{lcccc} 
& Total $(\mathbf{n = 8 0 0})$ & Female $(\mathbf{n = 5 5 4})$ & Male $(\mathbf{n = 2 4 6})$ & p value \\
\hline Age & $50.2 \pm 16.0$ & $51.6 \pm 15.3$ & $46.9 \pm 17.0$ & $<0.001$ \\
Gissane & $110.6 \pm 11.9$ & $110.8 \pm 11.7$ & $110.0 \pm 12.4$ & 0.391 \\
\hline Bohler & $32.6 \pm 6.1$ & $32.4 \pm 6.1$ & $33.1 \pm 6.1$ & 0.165 \\
\hline $15-20$ & $26(3.2)$ & $12(2.2)$ & $14(5.7)$ & \\
$21-30$ & $74(9.2)$ & $39(7.0)$ & $35(14.2)$ & \\
$31-60$ & $126(15.8)$ & $84(15.2)$ & $42(17.1)$ & \\
$41-50$ & $160(20.0)$ & $113(20.4)$ & $47(19.1)$ & \\
\hline $51-60$ & $199(24.9)$ & $149(26.9)$ & $50(20.3)$ & \\
$61-92$ & $215(26.9)$ & $157(28.3)$ & $58(23.6)$ & \\
\hline
\end{tabular}

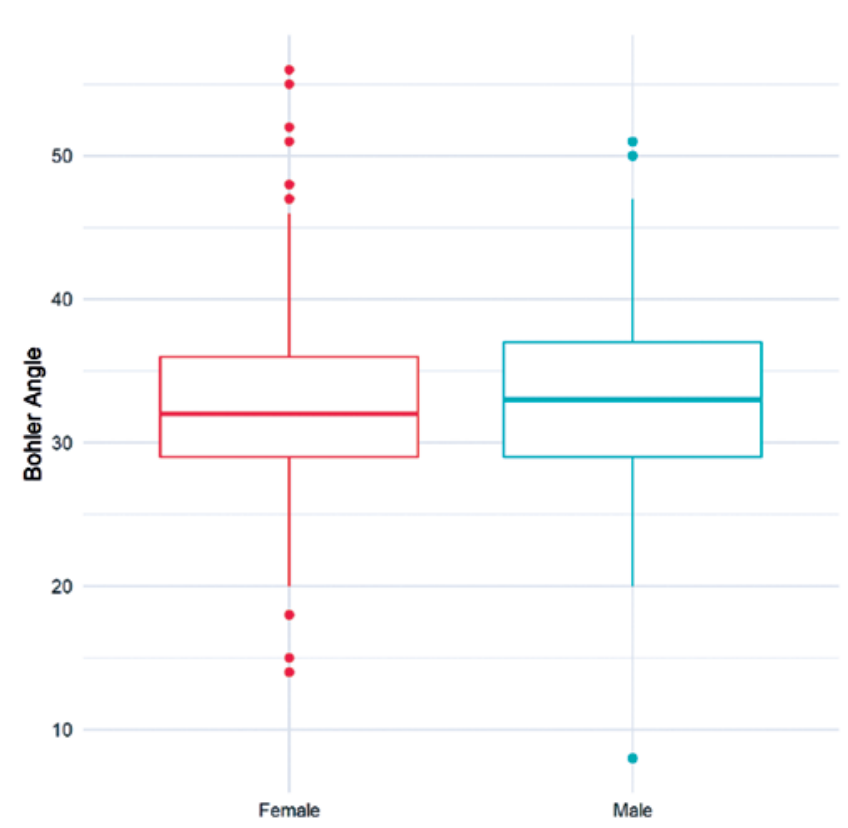

Figure 3. Böhler compared between sexes. difference when we compare the Böhler angle found in Brazil with the Nigerian ${ }^{(9)}$, Turkish(10), and Croatian(11) populations. There was a statistically significant difference in relation to the Gissane angle found in all the studies evaluated, and in the Böhler angle when compared with American(12), Ugandan $^{(13)}$, Saudi $^{(7)}$, Egyptian $^{(14)}$, Serbian $^{(15)}$, Australian $^{(16)}$, British $^{(17)}$, and Indian subjects ${ }^{(18)}$.

\section{Discussion}

The Böhler and Gissane angles were described in 1931 and 1947 respectively, before the creation of computed tomography in the 1960s. Therefore, for a long time they were the only radiographic parameters used to assess joint impairment in calcaneal fractures. Today, now that the use of tomography has become increasingly popular in many parts of the world,

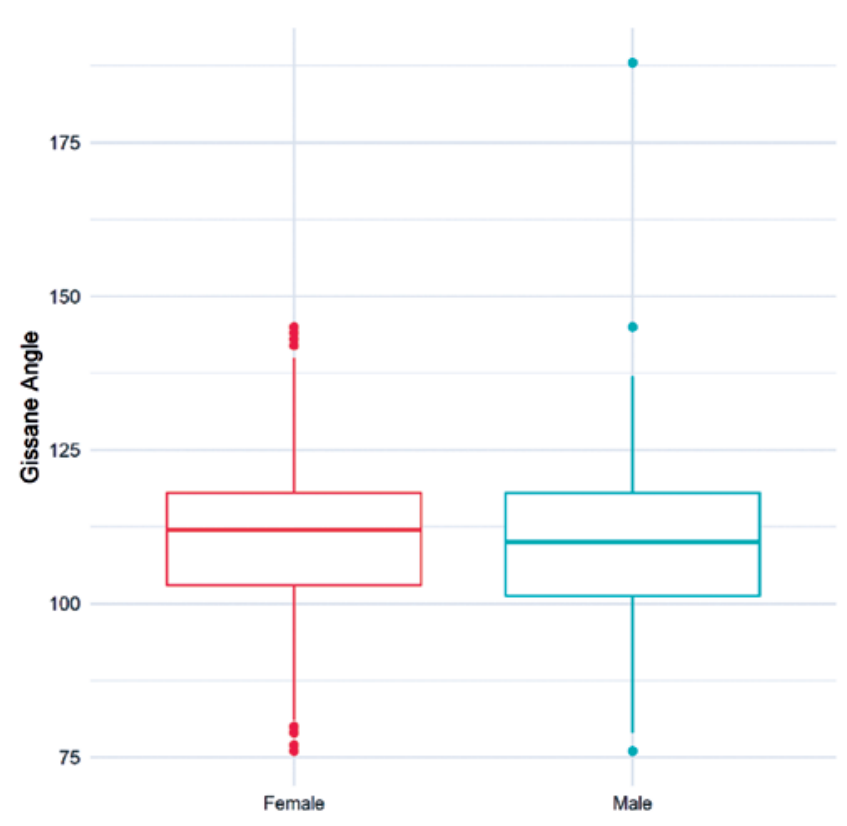

Figure 4. Gissane compared between sexes.

Table 3. Comparison between age groups

\begin{tabular}{|lccc|}
\hline Age groups & Cases (\%) & Böhler angle & Gissane angle \\
\hline $18-20$ & $26(3.2)$ & $33.2 \pm 8.7$ & $114.7 \pm 19.7$ \\
\hline $21-30$ & $74(9.2)$ & $34.0 \pm 5.5$ & $106.7 \pm 11.0$ \\
\hline $31-60$ & $126(15.8)$ & $32.9 \pm 5.7$ & $110.9 \pm 10.7$ \\
\hline $41-50$ & $160(20.0)$ & $32.5 \pm 5.7$ & $111.7 \pm 12.3$ \\
\hline $51-60$ & $199(24.9)$ & $31.8 \pm 6.9$ & $111.3 \pm 11.1$ \\
\hline $61-92$ & $215(26.9)$ & $32.9 \pm 5.5$ & $109.6 \pm 12.0$ \\
$P$ & & 0.011 & 0.151 \\
\hline
\end{tabular}


Table 4. Comparison with the literature

\begin{tabular}{|c|c|c|c|}
\hline Population & no & Mean $(9)$ & p \\
\hline Chen et al. (American) & 120 & $B A: 30 \pm 6$ & 0.001 \\
\hline $\begin{array}{l}\text { Igbigbi and Mutesasira } \\
\text { (Uganda) }\end{array}$ & 114 & $\begin{array}{l}\text { BA: } 35.1 \pm 7.5(F) \\
B A: 37.6 \pm 5.6(\mathrm{M})\end{array}$ & $\begin{array}{c}0.001 \\
<0.001\end{array}$ \\
\hline Didia and Dimkpa (Nigerian) & 302 & BA: $32.8 \pm 2.8$ & 0.533 \\
\hline Khoshhal et al. (Saudi) & 229 & $\begin{array}{l}\text { BA: } 31.2 \pm 5.6 \\
\text { GA: } 116.2 \pm 8.5\end{array}$ & $\begin{array}{l}<0.001 \\
<0.001\end{array}$ \\
\hline Seyahi et al. (Turkish) & 308 & $\begin{array}{l}\text { BA: } 33.8 \pm 4.8 \\
\text { GA: } 115.0 \pm 6.5\end{array}$ & $\begin{array}{l}0.026 \\
<0.001\end{array}$ \\
\hline Shoulry et al. (Egypt) & 220 & $\begin{array}{l}\text { BA: } 30.15 \pm 4.18 \\
\text { GA: } 122.92 \pm 6.9\end{array}$ & $\begin{array}{l}<0.001 \\
<0.001\end{array}$ \\
\hline Macuzic et al. (Serbian) & 225 & BA: $34.1 \pm 4.2$ & $<0.001$ \\
\hline Isaacs et al. (Australian) & 212 & BA: $29.4 \pm 4.1$ & $<0.001$ \\
\hline Willmott et al. (British) & 127 & BA: $36.4 \pm 4.2$ & $<0.001$ \\
\hline Sengodan et al. (Indian) & 324 & $\begin{array}{l}\text { BA: } 30.62 \pm 5.77 \\
\text { GA: } 126.79 \pm 7.88\end{array}$ & $\begin{array}{l}<0.001 \\
<0.001\end{array}$ \\
\hline Simunovic et al. (Croatian) & 130 & BA: $33.73 \pm 5.17$ & 0.030 \\
\hline
\end{tabular}

they are still being used to assess these fractures, helping orthopedists make therapeutic decisions, and to assess the outcome of surgical treatment. Studies have shown a relationship between normalization of the Böhler angle in the postoperative period and better clinical and functional outcomes ${ }^{(19,20)}$. In addition, a biomechanical study found a correlation between the Gissane angle after restoration and the "Second Peak of Force", indicating that the better the reduction of this angle, the better the impulsion. A correlation was also found between the rating system proposed by the American Orthopaedic Foot \& Ankle Society (AOFAS) and the First Peak of Force (ground reaction force upon initial contact of the foot in the support phase), showing that the better the clinical outcome, the better the hindfoot support ${ }^{(21)}$.

Although they have been described and used for many decades, including in Brazil, there were no studies determining normal values in this population. The sample evaluated here (800 patients) is the largest when compared to other studies available in the literature, and enabled us to determine that the value of the Gissane angle in the Brazilian population is $110.6 \pm 11.9$, while that of the Böhler angle is 32.6 \pm 6.1 . No difference was observed between different age groups and between males and females, showing that no variation in these values is expected after skeletal maturity. These findings are compatible with other studies available in the literature ${ }^{(7,9,10,14)}$.

In the statistical comparison with the results of 11 published articles that assessed different populations, it is important to note that a statistically significant difference was observed between the Gissane angle in the Brazilian population and all others available in the literature. Regarding the Böhler angle found in this particular study, no statistically significant difference was observed in the comparison only with the Nigerian $^{(9)}$, Turkish(10) and Croatian populations ${ }^{(11)}$. There was a statistically significant difference with the other eight studies evaluated.

Despite the importance of plain radiography and the preand postoperative evaluation of the Böhler and Gissane angles, tomography plays an increasingly essential role in the management of this complex lesion. In the preoperative evaluation, tomography enables us to accurately locate the different fractured bone fragments, facilitating surgical planning. Consequently, there is better joint alignment in patients undergoing osteosynthesis with prior tomographic evaluation when compared to those who have undergone radiographs alone ${ }^{(22)}$.

These findings show the importance of studies assessing the particularities of the radiographic parameters of the musculoskeletal system in different populations, since the data available in the literature may not be suitable for certain regions.

The main limitation of the study concerns the fact that it was carried out with a convenience sample of patients from a single Orthopedics and Traumatology clinic, and was not preceded by a pilot study.

\section{Conclusion}

In the Brazilian population, the Gissane angle is $110.6 \pm 11.9$, while the Böhler angle is $32.6 \pm 6.1$. There is no statistically significant difference in the comparison between sex and age.

Authors' contributions: Each author contributed individually and significantly to the development of this article: ECSL *(https://orcid.org/OOOO-OOO31230-8769) conceived and planned the activities that led to the study, wrote the article; TBF *(https://orcid.org/0000-0002-6122-3609) conceived and planned the activities that led to the study, wrote the article; TMP *(https://orcid.org/0000-0003-1644-2244) participated in the review process, approved the final version; LDSF *(https://orcid.org/0000-0002-4019-2639) participated in the review process, approved the final version; RGZ *(https://orcid. org/0000-0003-1555-2038) participated in the review process, approved the final version; TAA *(https://orcid.org/0000-0002-0124-3448) participated in the review process, approved the final version. *ORCID (Open Researcher and Contributor ID) (iD). 


\section{References}

1. Mitchell MJ, McKinley JC, Robinson CM. The epidemiology of calcaneal fractures. Foot (Edinb). 2009;19(4):197-200.

2. Dhillon MS, Bali K, Prabhakar S. Controversies in calcaneus fracture management: a systematic review of the literature. Musculoskelet Surg. 2011;95(3):171-81.

3. Böhler L. Diagnosis, pathology and treatment of fractures of the os calcis. J Bone Joint Surg Am.1931;13(1):75-89.

4. Leung KS, Yuen KM, Chan WS. Operative treatment of displaced intra-articular fractures of the calcaneum. Medium-term results. J Bone Joint Surg Br. 1993;75(2):196-201.

5. O'Farrell DA, O'Byrne JM, McCabe JP, Stephens MM. Fractures of the os calcis: improved results with internal fixation. Injury. 1993;24(4):263-5.

6. Gissane W. Discussion on "Fractures of the os calcis". Proceedings of the British Orthopaedic Association. J Bone Joint Surg Am. 1947; 29:254-55.

7. Khoshhal KI, Ibrahim AF, Al-Nakshabandi NA, Zamzam MM, AlBoukai AA, Zamzami MM. Bohler's and Gissane's angles of the calcaneus in the Saudi population. Saudi Med J. 2004;25(12): 1967-70.

8. Schepers T, Ginai AZ, Mulder PG, Patka P. Radiographic evaluation of calcaneal fractures: to measure or not to measure. Skeletal Radiol. 2007;36(9):847-52.

9. Didia BC, Dimkpa JN. The calcaneal angle in Nigerians. Relationship to sex, age, and side of the body. J Am Podiatr Med Assoc. 1999;89(9):472-4

10. Seyahi A, Uludag S, Koyuncu LO, Atalar AC, Demirhan, M. The calcaneal angles in the Turkish population. Acta Orthop traumatol turc. 2009;43(5): 406-411.

11. Šimunović $M$, Nizić $D$, Pervan $M$, Radoš $M$, Jelić $M$, Kovačević $B$. The physiological range of the Böhler's angle in the adult Croatian population. Foot Ankle Surg. 2019;25(2):174-179.
12. Chen MY, Bohrer SP, Kelley TF. Boehler's angle: a reappraisal. Ann Emerg Med. 1991;20(2):122-4.

13. Igbigbi PS, Mutesasira AN. Calcaneal angle in Ugandans. Clin Anat. 2003;16(4):328-30.

14. Shoukry FA, Aref YK, Sabry AAE. Evaluation of the normal calcaneal angles in Egyptian population. Alex J Med. 2012;48(2):91-7.

15. Živanović-Mačužić I, Vulović $M$, Vojinović $R$, Jovanović $M$ Radunović A, Milev B. et al. The Böhler's angle in population of central Serbia: a radiological study. Vojnosanitetski pregled. 2018;75(3):241-5.

16. Isaacs JD, Baba M, Huang P, Symes M, Guzman M, Nandapalan H. et al. The diagnostic accuracy of Böhler's angle in fractures of the calcaneus. J Emerg Med. 2013;45(6):879-84.

17. Willmott H, Stanton J, Southgate C. Böhler's angle - What is normal in the uninjured British population? Foot Ankle Surg. 2012;18(3):187-9.

18. Sengodan VC, Amruth, K. Bohler's and Gissane angles in the Indian population. J Clin Imaging Sci. 2012;2:77.

19. Paley D, Hall H. Intra-articular fractures of the calcaneus. A critical analysis of results and prognostic factors. J Bone Joint Surg Am. 1993;75(3):342-54

20. Slatis P, Kiviluoto O, Santavirta S, Laasonen EM. Fractures of the calcaneum. J Trauma.1979;19(12):939-43.

21. Contreras MEK, Muniz AMDS, Souza JBD, Avila AOV, Borges Junior NG, Barbosa DRF. Biomechanical evaluation of intra articular calcaneal fracture and clinical radiographic correlation. Acta Ortopédica Brasileira. 2004;12(2):105-12.

22. Angthong C, Atikomchaiwong A, Yoshimura I, Kanazawa $\mathrm{K}$, Hamrnroongroj T, Angthong W, et al. Does the addition of computed tomography to computed radiography provide more value to final outcomes and treatment decisions in displaced intra-articular calcaneal fractures? J Med Assoc Thai. 2014;97 Suppl 9:S1-9. 